\title{
Microbiology of Rhinosinusitis and Antimicrobial Resistance
}

\author{
Nagehan Erdoğmuş Küçükcan, Sameer Ali Bafaqeeh, \\ and Suela Sallavaci
}

\subsection{Acute Rhinosinusitis}

Acute rhinosinusitis (ARS) is the inflammation of the nasal mucous membrane and can be separated into acute viral and acute bacterial rhinosinusitis. It is frequently observed after viral rhinitis or common cold [1].

\subsubsection{Viral ARS}

Viral, post-viral, and acute bacterial ARS (ABRS) display significantly similar clinical presentation and inflammatory mechanism. Viral infection of the sinus cavity can cause numerous changes such as post-viral inflammation and epithelial damage, which enhance the susceptibility to bacterial infection [1].

The most common virus families that cause ARS are coronavirus and rhinovirus. Approximately 50\% of common colds are caused by the human rhinovirus. Other viral offenders include parainfluenza, influenza, respiratory syncytial virus (RSV), adenovirus, and enterovirus [2].

\subsubsection{Common Bacteria in ABRS}

ABRS is generally accompanied by a viral upper respiratory tract infection. Multiple factors can predispose a person to bacterial infection by damaging normal mucociliary

\footnotetext{
N. E. Küçükcan ( $\triangle)$

Department of Otorhinolaryngology, Çukurova State Hospital, Adana, Turkey

S. A. Bafaqeeh

Facial Plastic Division, Department of Otolaryngology, King Saud University, Riyadh, Saudi Arabia

S. Sallavaci

Department of ORL-HNS, University Hospital Centre "Mother

Teresa", Tirana, Albania
}

clearance such as allergy/inflammatory diseases, environmental factors, dental infection, and anatomic variation among others [3].

The most widely recognized bacteria in ABRS are $S$. pneumonia, $H$. influenza, and $M$. catarrhalis and S. aureus, while other species and anaerobic bacteria may also contribute to the infection [4-6]. Interestingly, Payne and colleagues performed a meta-analytic study on reports about the microbiology of ABRS, which evaluated the most common bacterial occurrence within the sinus. The report showed that the maxillary sinus contained $H$. influenza, S. pneumoniae, $M$. catarrhalis, and S. aureus at 28\%, 26\%, 6\%, and 8\%, respectively. On the other hand, the same bacteria were found at $34 \%, 29 \%, 11 \%$, and $14 \%$, respectively, in the middle meatus [4]. Furthermore, Brook and Gober [7] showed that S. pneumoniae decreased from 44 to $27 \%$, while $H$. influenza, $S$. pyrogenes, and S. aureus increased from 37 to $44 \%$, from 7 to $12 \%$, and from 4 to $8 \%$, respectively, with no change in $M$. catarrhalis (from 13 to $14 \%$ ). These findings were determined from nasopharyngeal cultures taken from children before and after administration of a pneumococcal conjugate vaccine.

$S$. aureus is commonly associated with the pathogenesis of sphenoid sinusitis. The 7-valent pneumococcal vaccine was presented in the United States in 2000 and aided in the reduction of the recovery rate for $S$. pneumoniae and the increase in the rate of $H$. influenza [7, 8]. Additionally, the recovery rate against $S$. pneumoniae antibiotic-resistant strains was found to be diverse after vaccination.

Other gram-negative bacteria, including $P$. aeruginosa, have been determined to associate with nosocomial origin acute sinusitis, immunocompromised patients, and cystic fibrosis [3].

Approximately $66 \%$ of acute sinusitis patients were shown to have at least one pathogenic bacteria species within the sinus aspirates, while the others had multiple bacterial species. The bacteria associated with acute sinusitis colonized the normal nasal flora. Interestingly, these become pathogenic when they accumulate in the sinus [3]. 
Although the environment is sufficient and available for their growing, S. pyogenes, S. aureus, and other anaerobes are not as common with ABRS, and have been found in less than $10 \%$ of ABRS patients. Sinusitis that results from dental infection or chronic manifestations are the exceptions [3].

A study performed in 1998 on respiratory tract/paranasal sinuses isolates showed that $12.3 \%$ of $S$. pneumoniae were marginally resistant to penicillin, while $37.4 \%$ fully resistant. Interesting to note, the paranasal sinuses had the highest rate of resistance for bacteria isolated from that region [9]. Also, the resistance to trimethoprim-sulfamethoxazole, clindamycin, macrolide, and doxycycline was more common in with the bacteria with intermediate penicillin resistance. $H$. influenzae may be encapsulated or unencapsulated. The type $\mathrm{B}$ form was a marginal contributor to meningitis before the incorporation of the vaccine. Unencapsulated strains contribute to $22-35 \%$ of ABRS in adults. One of the biggest contributors to antimicrobial resistance is the beta-lactamase production in the organism. Interestingly, $32.7-44 \%$ of the isolates from the paranasal sinus were determined to be $H$. influenza beta-lactamase positive [3].

M. catarrhalis bacteria are responsible for $2-10 \%$ of the ABRS adult cases. Beta-lactamase also contributes to the antibiotic resistance in M. catarrhalis, in which $98 \%$ of the isolates from the paranasal sinus were beta-lactamase positive [3].

To date, S. aureus accounts for $10 \%$ of ABRS episodes, but is becoming a common pathogen in ABRS [10]. While MRSA (methicillin-resistant $S$. aureus) still contributes to a few rhinosinusitis episodes, growing developments in $S$. aureus drug-resistance may change our treatment strategies in the future [11].

Gram-negative organisms such as $P$. aeruginosa, E. coli, $P$. mirabilis, K. pneumoniae, and the Enterobacter species have been noticeable in the nosocomial sinusitis, which accounts for $60 \%$ of the known cases. Gram-positive organisms (31\%) and fungi (8.5\%) make up the other pathogens responsible for nosocomial infection [3]. Polymicrobial invasion has been observed in $25-100 \%$ of isolates.

\subsection{Chronic Rhinosinusitis (CRS) in the Absence or Presence of Nasal Polyps (CRSwNP or CRSsNP)}

CRSwNP and CRSsNP are composed of many forms and are common conditions in medicine [1].

\subsubsection{Inflammatory Triggers}

\subsubsection{Viruses}

Viruses are a source of CRS. They can integrate into host DNA and cause infection in the mucosa of the upper lungs.
A previous report demonstrated that the rhinovirus was found in $21 \%$ of epithelial cell specimens of CRS patients compared to none in the control cells [12]. Conversely, another study failed to confirm this finding and showed that no viruses were found in either group [13]. Altogether, these data do not indicate a role for virus infection and chronic inflammation in CRS.

The known mechanism that triggers virus-first event predisposing to the improvement of CRS is also lacking. Interestingly, viral infections at an early age have been connected to asthma, though this idea has not been proven in CRS [14]. It is believed that virus-induced epigenetic changes may occur in the host during the life development [15].

\subsubsection{CRS Nasal and Sinus Microbiota}

To date, microbiota analysis of the nasal and sinus from CRS patients has been performed using standard lab techniques. $S$. epidermidis levels were found to be higher in controls when compared to CRS [16]. Upon comparison of ARS and CRS, there was a greater increase in the levels of gramnegative rods, S. aureus, and anaerobes in CRS [17-25]. Moreover, other researchers determined that there was no difference between the bacteriology of CRS nasal and normal nasal swabs [26, 27]. Similar microbiological flora was observed for the infected and non-infected sides in cases of unilateral CRS [28]. In addition, the results of the culture were similar upon a successful sinus surgery [29]. All in all, these reports confirmed the bacterial role in the CRS pathogenesis. Although, a few of the differences were most likely due to the discrepancies in the procedures [17], associated allergic rhinitis [30], prior antibiotic administration and source of material (sinus or nasal). Interestingly, a few researchers neglect the role of S. epidermidis. The occurrence of organisms within epithelial cells $[31,32]$ or in biofilm possibly produce differences in the bacterial identification rate with traditional methods.

The bacteria in CRS vary in comparison to ARS. Bacteria have been recorded in many samples acquired by endoscopy or sinus puncture in CRS patients [33].

- Staphylococcus aureus (both MSSA and MRSA) [11]

- Staphylococci (coagulase-negative) (SCN)

- H. influenzae

- M. catarrhalis

- S. pneumoniae

- S. intermedius

- P. aeruginosa

- N. species

- other anaerobic bacteria [34, 35]

The exact role(s) of all microbes in the etiology of CRS are ambiguous in contrast to that of ARS. Numerous researchers are divided on the microbial etiology of CRS. The 
biggest difference may lie in the methods or techniques used. Multiple reports have shown that their methods for the anaerobe recovery are key (yield 50-70\% of samples) [35]. In specimens analyzed in the studies, variability in microbial growth may also be caused by exposure to various broadspectrum antibiotics in patients.

Jyonouchi and colleagues effectively induced CRS in rabbits by intrasinus inoculation of $B$. fragilis. Interestingly, they identified immunoglobulin $\mathrm{G}$ ( $\operatorname{IgG}$ ) antibodies and no $B$. fragilis in this organism [36]. This is consistent with previous reports that have identified IgG antibodies against anaerobic organisms in patients with CRS [37].

Microbiological reports of CRS regularly established that the infection was polymicrobial [34].

In some cases, the baseline CRS suddenly worsened or induced new symptoms. This acute exacerbation of CRS was found to be polymicrobial in many cases, with the anaerobic bacteria prevailing. Nevertheless, aerobic bacteria that are typically connected with ARS may appear [38].

Gram-negative facultative and aerobic bacteria have been more readily determined in CRS patients that underwent endoscopic sinus surgery [39].

$S$. aureus is the most commonly found bacteria in CRS patients in the western civilization [40]. Interestingly, its occurrence was shown to be much lower in Asian CRSwNP [41], but the microbial abundance did not command or eliminate its role in the pathogenesis. Host proof of bacteriaspecific effects exists for $S$. aureus. This suggests a role in the pathogenesis at least in a subgroup of CRSwNP patients. Substantial evidence concerning this organism in CRSwNP has accrued over the last ten years. This has brought about the "Staphylococcal Super-antigen Hypothesis," which states that $S$. aureus secretes super-antigenic toxins (SAgs) that augment local inflammation and polyps [42, 43].

\subsection{Antimicrobial Resistance}

Antibiotic resistance is a worldwide medical issue. Despite the beneficial technological advances, the improvement of new antimicrobial agents is currently moderate. Approximately all the developing countries are accepting a strategy to cut off and prevent antibiotic resistance by a complicated approach to improve public health. Since the most important reason of bacterial resistance is the misuse of these agents, the strategy should address the rational prescription of antibiotics. Planning nationwide antibiotic restriction programs can efficiently decrease the antibioticresistance rate [44].

Coagulase-negative Staphylococcus and S. aureus were the most frequently found gram-positive aerobes in patients with CRS, while $H$. influenzae and $P$. aeruginosa were frequently found in gram-negative aerobes. Though the precise role of these pathogens in the pathophysiology remains to be explained, they are often cultured in CRS patients and may be important as disease modifiers. Mainly, the foundation of the precise microbiology of CRS derived from endoscopic cultures is necessary to bring about accurate antimicrobial therapy. This is particularly important given the antibiotic resistance concerns in uncontrollable patients [45].

The growth of antibiotic resistance in ARS and CRS has been previously described. Hsu and colleagues [20] examined the bacteriology of outpatient CRS and compared the antimicrobial sensitivities of the bacteria with standard culture data. From March to August 1994, 113 new outpatients presented with CRS. A total of 34 patients had endoscopy-directed aerobic culture in the sinus cavity. Of the 48 cultures, 43 positive cultures yielded 72 isolates. The most commonly isolated organisms were $\mathrm{SCN}$ (28\%), $P$. aeruginosa (17\%), and S. aureus (13\%). SCN, P. aeruginosa, and Pneumococcus showed an enhanced antibiotic resistance when compared to non-urinary isolates. Also, 3 of the 6 patients with $P$. aeruginosa (50\%) were resistant to quinolone. These data suggest that patients with CRS have an enhanced susceptibility to antimicrobial resistance.

In clinical settings, broad-spectrum empirical antibiotics are frequently used. But, using these broad-spectrum antibiotics regardless of the type of specific pathogenic agents can cause increased bacterial resistance and virulence. The penicillin group is a sensible first-line antibiotic for the treatment of sinusitis in many geographic areas [46]. When first-line agents fail or there is a high prevalence of $\beta$-lactamase resistance, second or third-generation cephalosporins as well as quinolones supply broader coverage [46]. Nevertheless, because of the wide distribution of bacterial resistance to these agents, limiting the inappropriate use of these antibiotics has been strongly considered [44].

Bhattacharyya and Kepnes [47] carried out a crosssectional evaluation of a prospective database in hopes of determining the present incidence and transient patterns of antimicrobial resistance in CRS. In adults with CRS, a microbiological database was retrospectively analyzed to remove all endoscopic obtained paranasal sinus cultures from 2001 to 2005. They studied 701 bacterial cultures among 392 isolates. S. aureus was the most common organism (19.0\%) isolated. Antibiotic resistance increased dramatically for erythromycin in the study $(69.7 \%$ in 2005 , $p=0.009)$, and remained unchanged or trended downward for other antibiotics used $(p=0.366$ to $p=0.397201$ or $p=0.180$ and $p=0.120)$. Nineteen percent of $S$. aureus bacteria were found to be MRSA. However, MRSA-specific antibiotic resistance rates were not changed over the study (all $p \geq 0.222$ ). The MRSA bacteria showed a statistical and significant increase in the rate of resistance for each antibiotic tested compared to non-MRSA. Collectively, they concluded that antibiotic resistance was developing for erythromycin at 
a higher rate than the other antibiotics. MRSA preserves a substantial occurrence in CRS with an associated level increase for antibiotic resistance.

Correctly obtained bacterial isolates and local antibiotic resistance patterns should guide the decision of antimicrobial treatment. The common recovery of anaerobes (often $\beta$-lactamase positive) and of MRSA in chronic maxillary sinusitis recommends the use of antimicrobial agents that are effective for the treatment of these organisms [48].

In the last years, sinusitis has become a challenge and choosing the precise antimicrobial agent has become more complex. This is most likely because the predominant bacterial pathogens have grown resistant to the commonly used antibiotics [49].

Three major mechanisms of resistance to penicillin are [49]:

- "Blockage" of porin channels

- Beta-lactamase production

- Alteration in the penicillin-binding protein site

\subsubsection{Beta-Lactamase}

\section{Beta-lactamase producing bacteria (BLPB) in sinusitis.}

- One-third of ARS or CRS had BLPB isolation.

- In infection, BLPB protects against penicillin in vitro and in vivo.

- "Shielding" and beta-lactamase activity were shown in ARS and CRS. Antimicrobial therapy administration for the eradication of BLPB [49].

- Oral antimicrobial agents against aerobic BLPB in ARS.

- Oral agents against BLPB in CRS are a combination of amoxicillin and clavulanic acid, clindamycin, and metronidazole (effective only against anaerobes) [49].

\subsubsection{Streptococcus pneumoniae Resistance}

- S. pneumonia, penicillin resistance, and variation in penicillin-binding proteins.

- The national rate of resistance is over $35 \%$ of all isolates.

- To date, penicillin-resistant strains are $66 \%$ highly resistant.

- Penicillin-resistant strains are generally resistant to other antibiotics [49].

\subsubsection{Risk Factors for Infection Due to Antimicrobial-Resistant Bacteria}

Bacterial resistance to antibiotics has increased steadily over the years. Several factors can account for the increased resis- tance including prophylaxis, daycare, seasons, hospitalization, infection, communicable resistance, and/or family history of smoking [49].

\section{References}

1. Fokkens WJ, Lund VJ, Mullol J, et al. European Position Paper on rhinosinusitis and nasal polyps 2012. Rhinology. 2012;supplement 23:1-298.

2. Heikkinen T, Jarvinen A. The common cold. Lancet. 2003;361(9351):51-9.

3. Brook I. Bronze MS, editor. Acute sinusitis: Medscape. http:// emedicine.medscape.com/article/232670-overview\#showall. Accessed 5 Aug 2015.

4. Payne SC, Benninger MS. Staphylococcus aureus is a major pathogen in acute bacterial rhinosinusitis: a metaanalysis. Clin Infect Dis. 2007;45(10):e121-7.

5. Anonymous. Antimicrobial treatment guidelines for acute bacterial rhinosinusitis. Otolaryngol Head Neck Surg. 2004;130(1 SUPPL): $1-45$

6. Brook I. Bacteriology of acute and chronic frontal sinusitis. Arch Otolaryngol Head Neck Surg. 2002;128(5):583-5.

7. Brook I, Gober AE. Frequency of recovery of pathogens from the nasopharynx of children with acute maxillary sinusitis before and after the introduction of vaccination with the 7-valent pneumococcal vaccine. Int J Pediatr Otorhinolaryngol. 2007;71(4):575-9.

8. Brook I, Foote PA, Hausfeld JN. Frequency of recovery of pathogens causing acute maxillary sinusitis in adults before and after introduction of vaccination of children with the 7-valent pneumococcal vaccine. J Med Microbiol. 2006;55:943-6.

9. Jacobs MR, Bajaksouzian S, Windau A, Good CE, Lin G, Pankuch GA, et al. Susceptibility of Streptococcus pneumoniae, Haemophilus influenzae, and Moraxella catarrhalis to 17 oral antimicrobial agents based on pharmacodynamic parameters: 19982001 U S Surveillance study. Clin Lab Med. 2004;24(2):503-30.

10. Payne SC, Benninger MS. Staphylococcus aureus is a major pathogen in acute bacterial rhinosinusitis: a meta-analysis. Clin Infect Dis. 2007;45(10):e121-7. [Medline].

11. Brook I, Foote PA, Hausfeld JN. Increase in the frequency of recovery of meticillin-resistant Staphylococcus aureus in acute and chronic maxillary sinusitis. J Med Microbiol. 2008;57:1015-7.

12. Jang YJ, Kwon HJ, Park HW, Lee BJ. Detection of rhinovirus in turbinate epithelial cells of chronic sinusitis. Am J Rhinol. 2006;20(6):634-6.

13. Wood AJ, Antoszewska H, Fraser J, Douglas RG. Is chronic rhinosinusitis caused by persistent respiratory virus infection? Int Forum Allergy Rhinol. 2011;1(2):95-100.

14. Sigurs N. Epidemiologic and clinical evidence of a respiratory syncytial virusreactive airway disease link. Am J Resp Crit Care Med. 2001;163(3 Pt 2):S2-6.

15. Sly PD, Kusel M, Holt PG. Do early-life viral infections cause asthma? J Allergy Clin Immunol. 2010;125(6):1202-5.

16. Araujo E, Palombini BC, Cantarelli V, Pereira A, Mariante A. Microbiology of middle meatus in chronic rhinosinusitis. Am J Rhinol. 2003;17(1):9-15.

17. Meltzer EO, Hamilos DL, Hadley JA, Lanza DC, Marple BF, Nicklas RA, et al. Rhinosinusitis: establishing definitions for clinical research and patient care. J Allergy Clin Immunol. 2004;114(6 Suppl):155-212.

18. Doyle PW, Woodham JD. Evaluation of the microbiology of chronic ethmoid sinusitis. J Clin Microbiol. 1991;29(11):2396400.

19. Hoyt WH. Bacterial patterns found in surgery patients with chronic sinusitis. J Am Osteopath Assoc. 1992;92:205. 
20. Hsu J, Lanza DC, Kennedy DW. Antimicrobial resistance in bacterial chronic sinusitis. Am J Rhinol. 1998;12(4):243-8.

21. Jiang RS, Lin JF, Hsu CY. Correlations between bacteriology of the middle meatus and ethmoid sinus in chronic sinusitis. J Laryngol Otol. 2002;116:443-6.

22. Kim HJ, Lee K, Yoo JB, Song JW, Yoon JH. Bacteriological findings and antimicrobial susceptibility in chronic sinusitis with nasal polyp. Acta Otolaryngol. 2006;126(5):489-97.

23. Finegold SM, Flynn MJ, Rose FV, JousimiesSomer H, Jakielaszek $\mathrm{C}$, McTeague $\mathrm{M}$, et al. Bacteriologic findings associated with chronic bacterial maxillary sinusitis in adults. Clin Infect Dis. 2002;35(4):428-33.

24. Brook I. Microbiology of sinusitis. Proc Am Thorac Soc. 2011;8(1):90-100.

25. Mantovani K, Bisanha AA, Demarco RC, Tamashiro E, Martinez R, Anselmo-Lima WT. Maxillary sinuses microbiology from patients with chronic rhinosinusitis. Braz J Otorhinolaryngol. 2010;76(5):548-51.

26. Niederfuhr A, Kirsche H, Deutschle T, Poppert S, Riechelmann $\mathrm{H}$, Wellinghausen N. Staphylococcus aureus in nasal lavage and biopsy of patients with chronic rhinosinusitis. Allergy. 2008;63(10):1359-67.

27. Niederfuhr A, Kirsche H, Riechelmann H, Wellinghausen N. The bacteriology of chronic rhinosinusitis with and without nasal polyps. Arch Otolaryngol Head Neck Surg. 2009;135(2):1316.

28. Bhattacharyya N. Bacterial infection in chronic rhinosinusitis: a controlled paired analysis. Am J Rhinol. 2005;19(6):544-8.

29. Bhattacharyya N, Gopal HV, Lee KH. Bacterial infection after endoscopic sinus surgery: a controlled prospective study. Laryngoscope. 2004;114(4):765-7.

30. Shiomori T, Yoshida S, Miyamoto H, Makishima K. Relationship of nasal carriage of Staphylococcus aureus to pathogenesis of perennial allergic rhinitis. J Allergy Clin Immunol. 2000;105(3):449-54.

31. Clement S, Vaudaux P, Francois P, Schrenzel J, Huggler E, Kampf $S$, et al. Evidence of an intracellular reservoir in the nasal mucosa of patients with recurrent Staphylococcus aureus rhinosinusitis. J Infect Dis. 2005;192(6):1023-8.

32. Plouin-Gaudon I, Clement S, Huggler E, Chaponnier C, Francois $\mathrm{P}$, Lew D, et al. Intracellular residency is frequently associated with recurrent Staphylococcus aureus rhinosinusitis. Rhinology. 2006;44:249-54.

33. Brook I. Brusch JL, editor. Chronic sinusitis: Medscape. http:// emedicine.medscape.com/article/232791-overview\#showall. Accessed 5 Aug 2015.

34. Brook I. Acute and chronic bacterial sinusitis. Infect Dis Clin N Am. 2007;21(2):427-48

35. Brook I. Bacteriology of chronic maxillary sinusitis in adults. Ann Otol Rhinol Laryngol. 1989;98(6):426-8.
36. Incorvaia C, Leo G. Treatment of rhinosinusitis: other medical options. Int J Immunopathol Pharmacol. 2010;23(1 Suppl):70-3.

37. Brook I, Yocum P. Immune response to Fusobacterium nucleatum and Prevotella intermedia in patients with chronic maxillary sinusitis. Ann Otol Rhinol Laryngol. 1999;108(3):293-5.

38. Brook I, Foote PA, Frazier EH. Microbiology of acute exacerbation of chronic sinusitis. Laryngoscope. 2004;114:129-31.

39. Nadel DM, Lanza DC, Kennedy DW. Endoscopically guided cultures in chronic sinusitis. Am J Rhinol. 1998;12(4):233-41.

40. Larson DA, Han JK. Microbiology of sinusitis: does allergy or endoscopic sinus surgery affect the microbiologic flora? Curr Opin Otolaryngol Head Neck Surg. 2011;19(3):199-203.

41. Ba L, Zhang N, Meng J, Zhang J, Lin P, Zhou P, et al. The association between bacterial colonization and inflammatory pattern in Chinese chronic rhinosinusitis patients with nasal polyps. Allergy. 2011;66(10):1296-303. https://doi.org/10.1111/j.13989995.2011.02637.x. Epub 2011 May 17.

42. Bachert C, Gevaert P, Holtappels G, Johansson SG, van Cauwenberge P. Total and specific IgE in nasal polyps is related to local eosinophilic inflammation. J Allergy Clin Immunol. 2001;107(4):607-14.

43. Bachert C, Zhang N, Patou J, van Zele T, Gevaert P. Role of staphylococcal superantigens in upper airway disease. Curr Opin Allergy Clin Immunol. 2008;8(1):34-8.

44. Farahani F, Mashouf RY, Hashemian F, Esmaeili R. Antimicrobial resistance patterns of aerobic organisms in patients with chronic rhinosinusitis in Hamadan. Iran Avicenna J Clin Microb Infect. 2014;1(2):e18961.

45. Thanasumpun T, Batra PS. Endoscopically-derived bacterial cultures in chronic rhinosinusitis: a systematic review. Am J Otolaryngol. 2015;36(5):686-91. https://doi.org/10.1016/j. amjoto.2015.04.010.

46. Shanmugam S, Selvarajan R, Thangiah S. Drug resistance of Staphylococcus aureus in sinusitis patients. Int $\mathrm{J}$ Biosci. 2011;1(3):63-71.

47. Bhattacharyya N, Kepnes LJ. Assessment of trends in antimicrobial resistance in chronic rhinosinusitis. Ann Otol Rhinol Laryngol. 2008;117(6):448-52.

48. Puglisi S, Privitera S, Maiolino L, Serra A, Garotta M, Blandino $\mathrm{G}$, Speciale A. Bacteriological findings and antimicrobial resistance in odontogenic and non- odontogenic chronic maxillary sinusitis. J Med Microbiol. 2011;60(Pt 9):1353-9. https://doi.org/10.1099/ jmm.0.031476-0.

49. Brook I. Sinusitis understood. http://sinusitisunderstood.blogspot. com.tr/p/medical-management-antimicrobial.html. Accessed 5 Aug 2015. 